\title{
SISTEM INFORMASI PARIWISATA KABUPATEN PEMALANG SELATAN YANG BERBASIS WEB
}

\author{
Afina Nailun Ni'mah \\ Sistem Informasi, STMIK Muhammadiyah Jakarta, Indonesia \\ Email: afinanailun1@gmail.com
}

\begin{abstract}
The web-based South Pemalang Regency tourism information system is used as a tool in delivering information on tourist and cultural areas in Pemalang Regency to people who want to know tourist areas in Pemalang Regency. The web-based Pemalang Regency tourism information system is one form of regional tourism promotion in Pemalang Regency, in order to attract tourists to visit Pemalang Regency. The research methods used include direct observation, interviews with related parties, and literature studies related to the issues raised. The application development methodology that the author uses is the waterfall model. The programming language used is Sublime Text using mysql as the database. This research is useful as a medium of information and promotion of tourism potential in Pemalang Regency, so that people will be more familiar with regional tourism places in Pemalang Regency. The more tourists who visit, the income of the area and the surrounding community will increase.
\end{abstract}

Keyword: Information System, Tourism, Pemalang Regency.

\begin{abstract}
Abstrak
Sistem informasi pariwisata kabupaten pemalang selatan berbasis web digunakan sebagai alat bantu dalam penyampaian informasi kawasan wisata dan budaya yang ada di Kabupaten Pemalang kepada masyarakat yang ingin mengetahui daerah-daerah pariwisata yang ada di Kabupaten Pemalang. Sistem informasi pariwisata kabupaten pemalang berbasis web merupakan salah satu bentuk promosi pariwisata daerah yang ada di Kabupaten Pemalang, agar menarik para wisatawan untuk berkunjung ke Kabupaten Pemalang. Metode penelitian yang dilakukan antara lain melalui observasi langsung, wawancara dengan pihak terkait, serta studi literatur yang berhubungan dengan masalah yang diangkat. Metodologi pengembangan aplikasi yang penulis gunakan adalah dengan model waterfall. Bahasa pemrograman yang digunakan adalah Sublime Text dengan menggunakan mysql sebagai databasenya. Penelitian ini bermanfaat sebagai media informasi dan promosi potensi wisata yang ada di Kabupaten Pemalang, sehingga masyarakat akan lebih mengenal tempat-tempat pariwisata daerah yang ada di Kabupaten Pemalang. Semakin banyak wisatawan yang berkunjung maka pendapatan daerah dan masyarakat sekitarnya akan mengalami peningkatan.
\end{abstract}

Kata Kunci: Sistem Informasi; Pariwisata; Kabupaten Pemalang. 


\section{Pendahuluan}

Pada saat ini, perkembangan ilmu pengetahuan dan teknologi yang pesat di dunia telah membawa perubahan yang mengguncang bumi, karena membuat informasi yang diperoleh cepat, nyaman, dan akurat, tanpa dibatasi oleh lokasi dan waktu. Selain itu, keberadaan teknologi dapat mendorong pekerjaan manusia yang dilakukan oleh seseorang menjadi lebih efektif dan efisien (Sasongko \& Diartono, 2009).

Dengan kemajuan perekonomian dan perkembangan kesejahteraan masyarakat, keinginan masyarakat untuk berlibur semakin tinggi, dan masyarakat membutuhkan informasi tentang destinasi wisata yang menarik, sarana transportasi, dan lain-lain. Namun, pengunjung atau wisatawan sering mengalami kendala dan kesulitan dalam memperoleh informasi tersebut. Oleh karena itu, informasi sektor pariwisata harus disajikan secara tepat dan sistematis agar masyarakat atau wisatawan dapat dengan mudah memperoleh informasi tersebut (Mulyanto, 2009).

Sistem Informasi Pariwisata Pemalang Selatan berbasis internet diperlukan sebagai media dan sarana untuk memberikan informasi kepada masyarakat atau wisatawan yang ingin mengetahui objek wisata (wisata alam dan wisata budaya) yang ada di Kabupaten Pemalang. Selain berfungsi sebagai media penyampaian informasi, sistem informasi ini juga dapat digunakan sebagai bentuk publisitas (Romindo et al., 2020). Selain itu dengan adanya sistem informasi ini, target wisata di kawasan Kabupaten Pemalang akan lebih dipahami dan digunakan oleh masyarakat Kabupaten Pemalang. atau masyarakat luar, menjadi lebih mudah bagi pemerintah daerah untuk mengelola tempat wisata di Kabupaten Pemalang.

\section{Metode Penelitian}

Metode pengembangan aplikasi yang digunakan penulis adalah model waterfall, yaitu analisis, perancangan, implementasi, pengujian dan pemeliharaan. Bahasa pemrograman yang digunakan adalah Sublime Text dengan menggunakan mysql sebagai databasenya (Susanto, 2004).

Lokasi penelitian berada di Kabupaten Pemalang, Provinsi Jawa Tengah. Berada di kawasan Pemalang Selatan. Metode pengumpulan data meliputi wawancara, observasi dan daftar pustaka. Melakukan wawancara dengan manajer perjalanan dan mengamati tempat wisata (Rahardjo, 2011).

\section{Hasil dan Pembahasan}

Sistem Informasi Pariwisata Pemalang Selatan berbasis internet diperlukan sebagai media dan sarana untuk memberikan informasi kepada masyarakat atau wisatawan yang ingin mengetahui objek wisata (wisata alam dan wisata budaya) yang ada di Kabupaten Pemalang. Selain berfungsi sebagai media penyampaian informasi, sistem informasi ini juga dapat digunakan sebagai bentuk publisitas. Selain itu dengan adanya sistem informasi ini, target wisata di kawasan Kabupaten Pemalang akan lebih 
dipahami dan digunakan oleh masyarakat Kabupaten Pemalang atau masyarakat luar. Memudahkan pemerintah daerah dalam mengelola tempat wisata di Kabupaten Pemalang (Saputra, Cahyadi, \& Kridalaksana, 2016).

\section{Analisa Kebutuhan Hardware}

Dalam mengimplementasikan desain yang telah dijelaskan, diperlukan beberapa perangkat keras untuk menyajikan aplikasi sistem informasi ini (Kasih \& Simargolang, n.d.). Alat-alat yang dibutuhkan adalah sebagai berikut:

\section{Tabel 1. Kebutuhan perangkat keras (Hardware)}

\begin{tabular}{|c|c|c|}
\hline No & Jenis & Komponen \\
\hline 1 & CPU & Intel Pentium \\
\hline 2 & Memori (RAM) & $4 \mathrm{~GB}$ \\
\hline
\end{tabular}

\section{Analisa Kebutuhan Software (Perangkat Lunak)}

Dalam pembuatan sistem informasi manajemen arsip surat menyurat. STMIK Muhammadiyah Jakarta membutuhkan beberapa software untuk membantu melengkapi sistem informasi ini, yaitu:

Tabel 2. Kebutuhan perangkat lunak (Software)

\begin{tabular}{ccc}
\hline No. & Jenis & Komponen \\
\hline 1 & Software & Xampp \\
\cline { 3 - 3 } & & Wondershare Edraw \\
& & Max \\
\cline { 3 - 3 } & & Notepad++ \\
\cline { 3 - 3 } & & Bootstrap \\
\hline 2 & Database & MySQL \\
\hline 3 & Operation System & Windows 10
\end{tabular}

\section{Analisa Yang Berjalan}

Analisis saat ini menggunakan sistem manual yaitu penyebaran brosur dan poster sehingga sebagian wisatawan tidak dapat memperoleh informasi apapun. 
Sistem Informasi Pariwisata Kabupaten Pemalang Selatan Berbasis Web

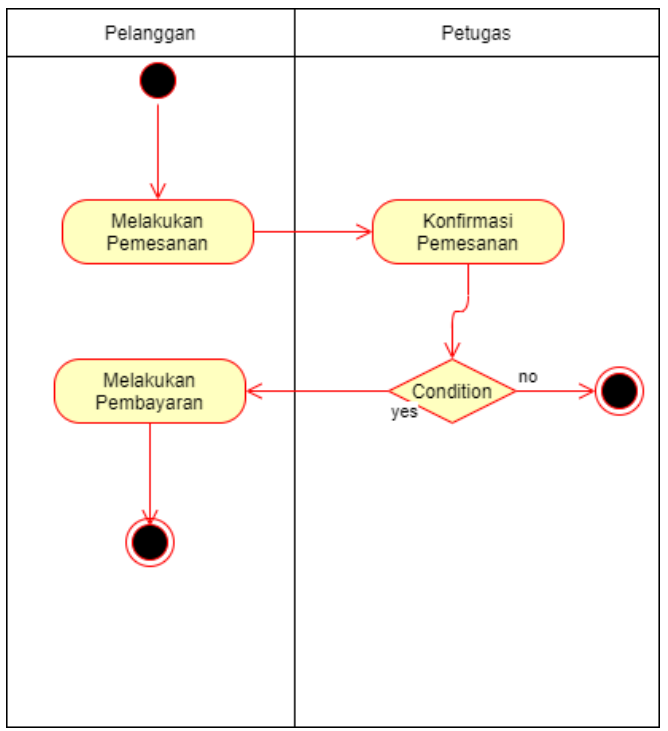

Gambar 1. Analisa yang Berjalan

4. Analisa sistem yang diusulkan

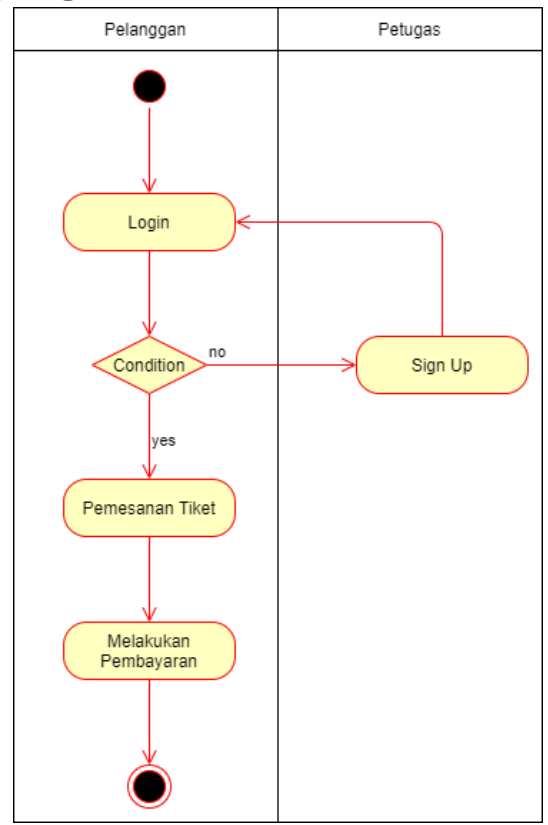

\section{Gambar 2. Analisa yang diusulkan}

Pada analisis yang diusulkan, hasil yang diperoleh adalah membuat situs web informasi sebagai pengganti brosur dan poster sehingga pengunjung dapat dengan mudah melihat informasi di situs web yang disediakan (Mertayasa \& Yambese, 2017).

Implementasi

1. Halaman Beranda 

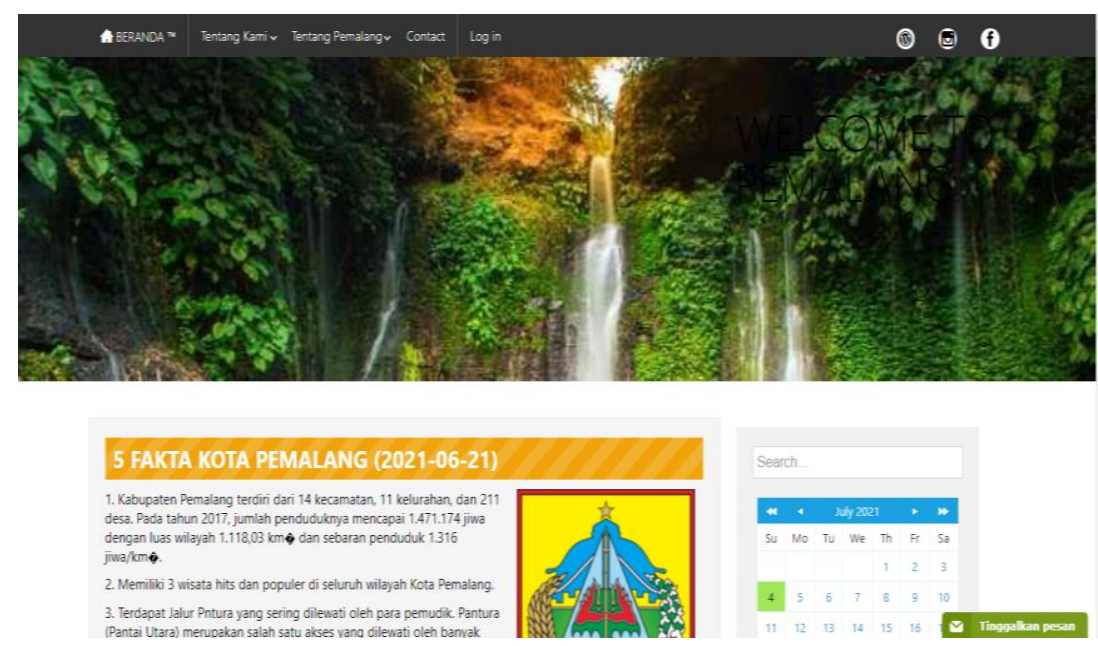

\section{Gambar 3. Halaman Beranda}

Layar utama adalah layar pertama yang muncul saat Anda menghidupkan sistem. Terdapat beberapa menu pada header homepage sistem ini yaitu menu homepage, about us, about Hachimarang, contact information dan menu login.

2. Halaman Daftar Wisata

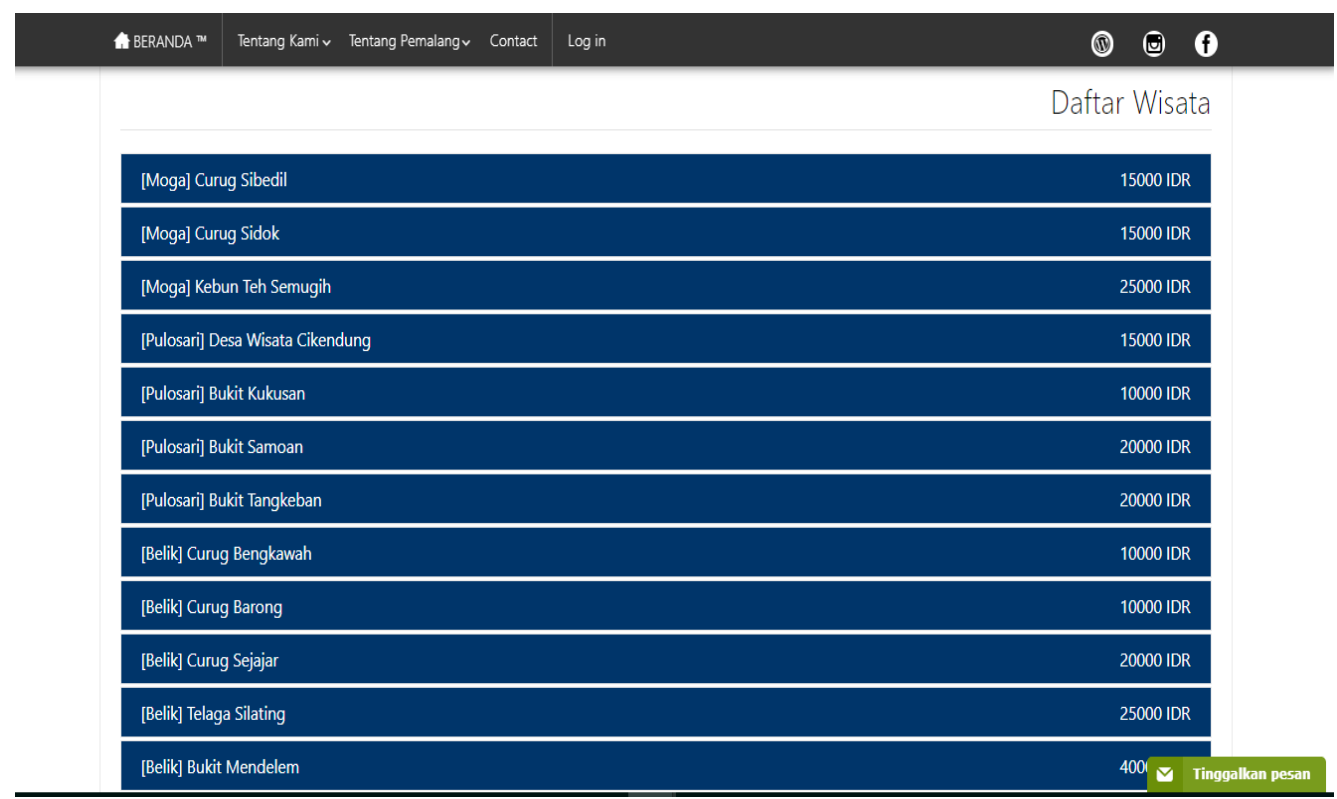

\section{Gambar 4. Halaman Daftar Wisata}

Pada halaman tempat wisata ini, Anda dapat memilih destinasi wisata di Kabupaten Pemalang. Wisatawan dapat memilih atraksi wisata yang ingin ditampilkan, dan setelah diseleksi, sistem akan menampilkan deskripsi objek wisata sesuai dengan atraksi yang dipilih.

3. Halaman Login 


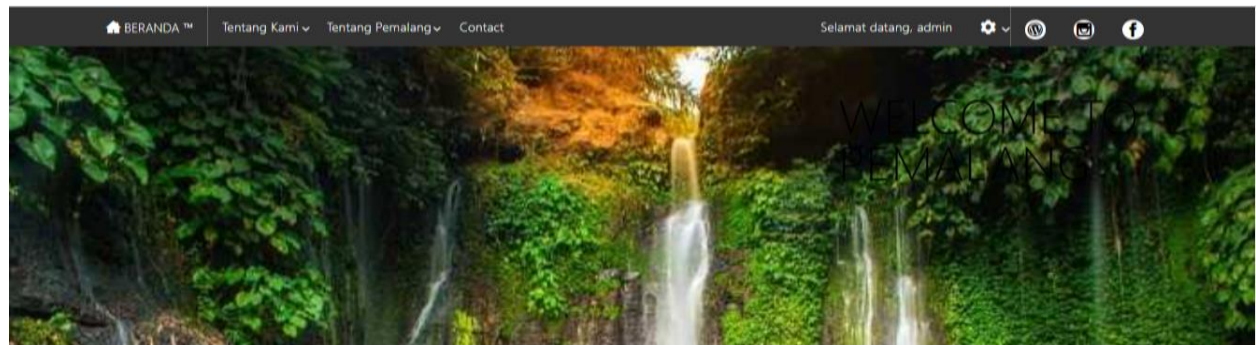

Administrator

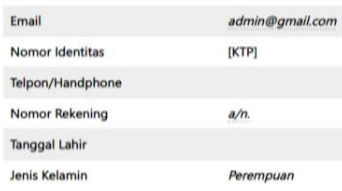

Gambar 5. Halaman Login

Pada halaman login, administrator harus mengisi form username dan password yang telah didaftarkan pada sistem. Kemudian klik login untuk masuk ke panel manajemen, jika nama pengguna atau kata sandi tidak valid, halaman tidak akan bergerak.

4. Halaman Sign Up
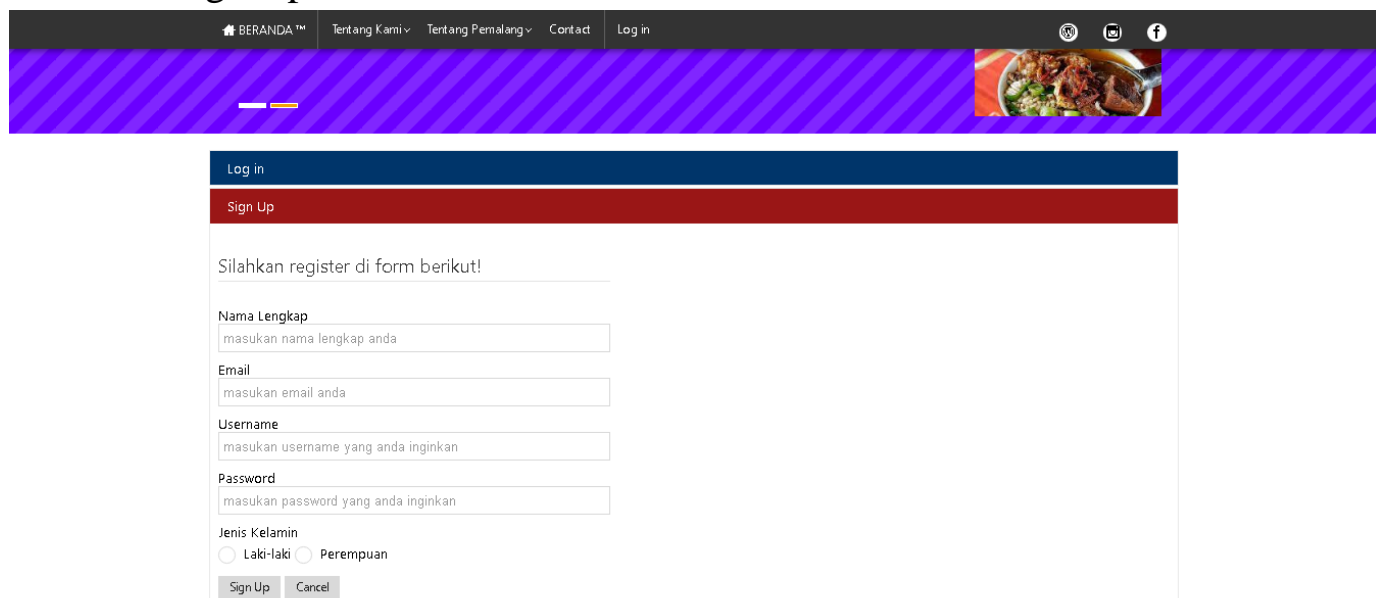

Gambar 6. Halaman Sign Up

Pada halaman pendaftaran, Anda harus mengisi formulir nama, email, username dan password, dan jenis kelamin untuk didaftarkan dalam sistem. Kemudian klik Daftar untuk mendaftar. Jika pendaftaran Anda berhasil, Anda akan diarahkan ke halaman login dan menerima pesan pendaftaran berhasil.

5. Halaman Profil Admin 


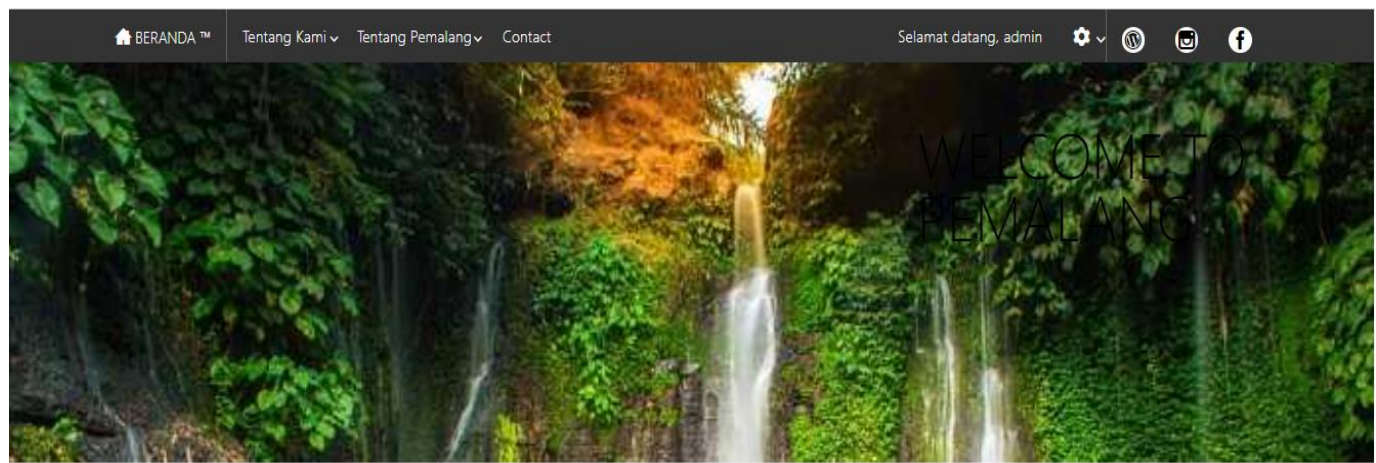

Administrator

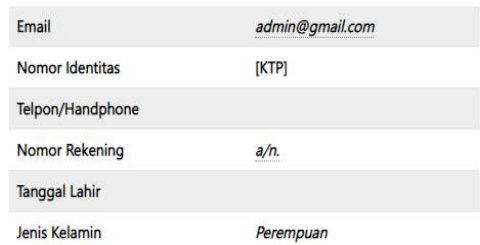

Gambar 7. Halaman Profil Admin

Tampilan halaman profil Admin adalah yang akan tampil pertama kali pada saat membuka jendela jika anda berhasil login, yang menjelaskan tentang deskripsi dari akun anda.

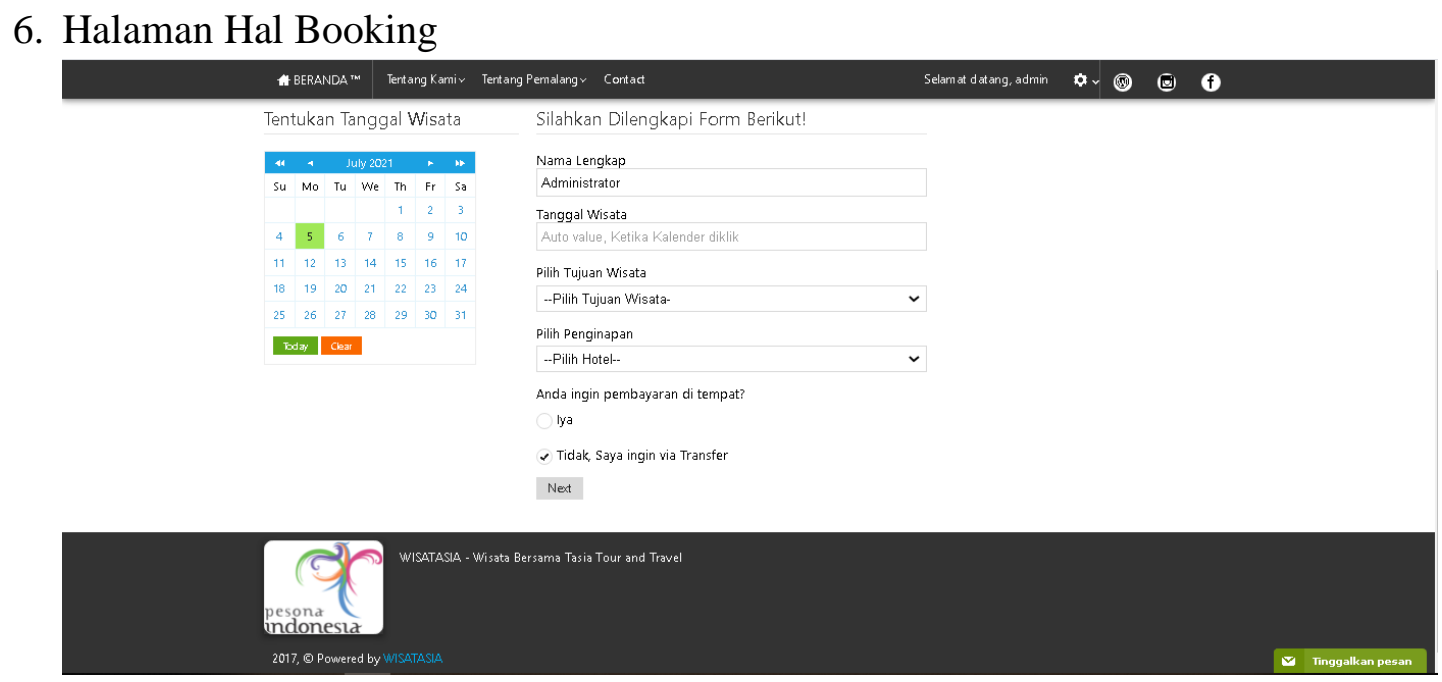

\section{Gambar 8. Halaman Hal Booking}

Pada halaman pemesanan, Anda harus mengisi nama Anda, tanggal perjalanan, tujuan perjalanan, memilih akomodasi dan memilih metode pembayaran. Setelah pemesanan berhasil, Anda akan diarahkan ke halaman cek pemesanan (Basuki, 2012).

7. Halaman Cek Booking 


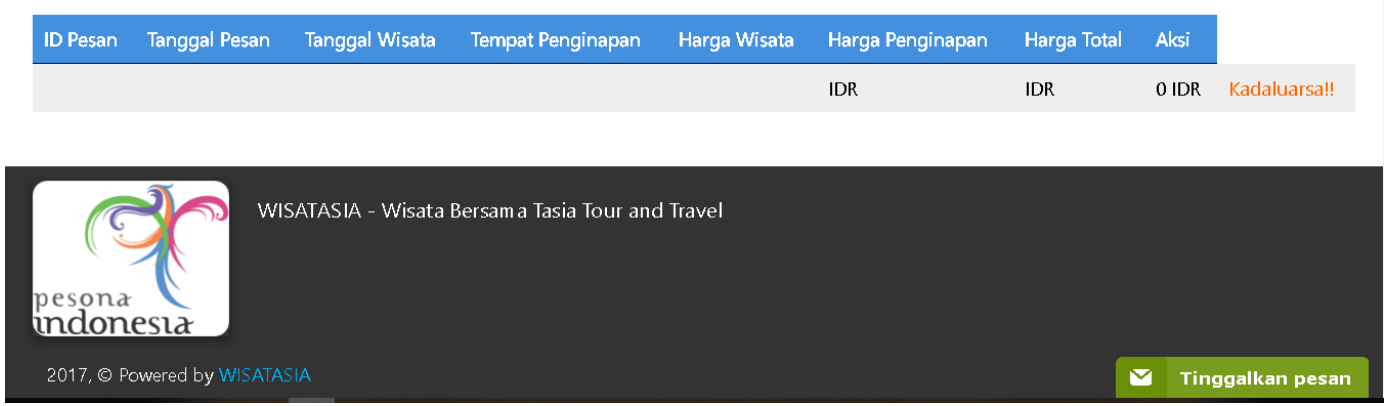

Gambar 9. Halaman Cek Booking

Pada halaman cek Booking anda akan melihat informasi tentang pemesanan anda.

\section{Pengujian}

Pengujian dilakukan untuk mengetahui apakah fungsi yang telah dibuat berjalan sesuai dengan yang diinginkan.

Pengujian login

\section{Tabel 3. Pengujian Login}

No Fungsi yang Diuji Detail Uji Jenis

\begin{tabular}{|c|c|c|c|}
\hline & & & Pengujian \\
\hline 1. & Login & $\begin{array}{l}\text { User } \\
\text { melakukan } \\
\text { login }\end{array}$ & Black Box \\
\hline 2. & Logout & $\begin{array}{l}\text { User } \\
\text { melakukan } \\
\text { logout }\end{array}$ & Black Box \\
\hline
\end{tabular}

Pengujian Proses

Tabel 4. Pengujian Proses

\begin{tabular}{llll} 
No & $\begin{array}{l}\text { Fungsi Yang } \\
\text { diuji }\end{array}$ & Detail Uji & $\begin{array}{l}\text { Jenis } \\
\text { Pengujian }\end{array}$ \\
\hline 1. & Tambah User & $\begin{array}{l}\text { Melakukan } \\
\text { Penambahan } \\
\text { Data User }\end{array}$ & Black Box \\
& & Melakukan & Black Box \\
& Pengeditan Data & \\
\hline 2. & Edit User & User & Black Box \\
& & Melakukan & \\
\hline 3. & Edit Password & Pengeditan & Black Box
\end{tabular}

Hasil Pengujian Login 
Tabel 5. Hasil Pengujian Login

\begin{tabular}{lllll}
\multirow{2}{*}{ No } & Fungsi & Skenario Uji & \multicolumn{1}{c}{$\begin{array}{c}\text { Hasil yang } \\
\text { Diharapakan }\end{array}$} & Hasil \\
\hline \multirow{2}{*}{1} & Login & Login (Jika Sesuai) & $\begin{array}{l}\text { Masuk Ke } \\
\text { Halaman Admin }\end{array}$ & Sesuai \\
\cline { 3 - 4 } & Login (Jika Salah) & $\begin{array}{l}\text { Tampil Konfirmasi } \\
\text { Login Gagal }\end{array}$ & Sesuai \\
\hline 3 & Logout & Logout & $\begin{array}{l}\text { Kembali Ke Menu } \\
\text { Login }\end{array}$ & Sesuai
\end{tabular}

Hasil Pengujian Proses

Tabel 6. Hasil Pengujian Proses

\begin{tabular}{|c|c|c|c|c|}
\hline No & Fungsi & Skenario Uji & $\begin{array}{l}\text { Hasil yang } \\
\text { Diharapakan }\end{array}$ & Hasil \\
\hline \multirow[b]{4}{*}{1} & \multirow[b]{4}{*}{ Tambah User } & Tambah User (Jika & Tambah Data User & \\
\hline & & Benar) & Berhasil & Sesuai \\
\hline & & Tambah User (Jika & Tambah Data User & \\
\hline & & Salah) & Gagal & Sesuai \\
\hline \multirow[b]{2}{*}{2} & \multirow[b]{2}{*}{ Edit User } & $\begin{array}{l}\text { Edit Data User } \\
\text { (Jika Benar) }\end{array}$ & $\begin{array}{l}\text { Edit Data User } \\
\text { Berhasil }\end{array}$ & Sesuai \\
\hline & & $\begin{array}{l}\text { Edit Data User } \\
\text { (Jika Salah) }\end{array}$ & Edit Data User Gagal & Sesuai \\
\hline \multirow{4}{*}{3} & \multirow{4}{*}{ Edit Password } & $\begin{array}{l}\text { Edit Password User } \\
\text { (Jika Benar) }\end{array}$ & $\begin{array}{l}\text { Edit Password User } \\
\text { Berhasil }\end{array}$ & Sesuai \\
\hline & & $\begin{array}{l}\text { Edit Password User } \\
\text { (Jika Salah) }\end{array}$ & $\begin{array}{l}\text { Edit Password User } \\
\text { Gagal }\end{array}$ & Sesuai \\
\hline & & Hapus User (Jika & Hapus Data User & \\
\hline & & Benar) & Berhasil & Sesuai \\
\hline 4 & Hapus User & $\begin{array}{l}\text { Hapus User (Jika } \\
\text { Salah) }\end{array}$ & $\begin{array}{l}\text { Hapus Data User } \\
\text { Gagal }\end{array}$ & Sesuai \\
\hline
\end{tabular}

\section{Kesimpulan}

Berdasarkan pembahasan pada perancangan dan pembuatan Sistem Informasi Pariwisata Kabupaten Pemalang Selatan berbasis jaringan, maka dapat disimpulkan bahwa Sistem Informasi Pariwisata Kawasan Pemalang Selatan berbasis jaringan yang dapat membantu masyarakat mendapatkan informasi tentang pariwisata yang ada industri dan mempromosikan penyebaran informasi. Sistem informasi pariwisata memberikan informasi kepada pengguna atau wisatawan untuk mencari informasi tentang pariwisata, budaya dan kuliner. Dengan adanya sistem informasi ini diharapkan dapat menjadi media untuk mempromosikan pariwisata di Kabupaten Pemalang kepada masyarakat di luar Kabupaten Pemalang. 


\section{BIBLIOGRAFI}

Basuki, Agung. (2012). Wisata Hemat: Singapura. Elex Media Komputindo. Google Scholar

Kasih, Fitri, \& Simargolang, Muhammad Yasin. (n.d.). Perancangan Chatting Room Berbasis Network. CESS (Journal of Computer Engineering, System and Science), 1(2), 39-43. Google Scholar

Mertayasa, Dewa Made, \& Yambese, Abd Rizal. (2017). Sistem Informasi Pariwisata Pantai Berbasis Web Pada Dinas Pariwisata dan Ekonomi Kreatif Kabupaten Banggai Kepulauan. Jurnal Elektronik Sistem Informasi Dan Komputer, 3(1), 5162. Google Scholar

Mulyanto, Agus. (2009). Sistem Informasi konsep dan aplikasi. Yogyakarta: Pustaka Pelajar, 1, 1-5. Google Scholar

Rahardjo, Mudjia. (2011). Metode pengumpulan data penelitian kualitatif. Google Scholar

Romindo, Romindo, Niar, Hikma, Sipayung, Rosintan, Julyanthry, Julyanthry, Yendrianof, Devi, Pelu, Muhammad Faisal A. R., Febrianty, Febrianty, Jamaludin, Jamaludin, Ardiana, Dewa Putu Yudhi, \& Simarmata, Janner. (2020). Sistem Informasi Bisnis. Yayasan Kita Menulis. Google Scholar

Saputra, Doni, Cahyadi, Dedy, \& Kridalaksana, Awang Harsa. (2016). Sistem Otomasi Perpustakaan Dengan Menggunakan Radio Frequency Identification (RFID). Informatika Mulawarman: Jurnal Ilmiah Ilmu Komputer, 5(3), 1-7. Google Scholar

Sasongko, Jati, \& Diartono, Dwi Agus. (2009). Rancang Bangun Sistem Informasi Manajemen Surat. Dinamik, 14(2). Google Scholar

Susanto, Azhar. (2004). Azhar Susanto, 2004, Sistem Informasi Akuntansi Edisi Pertama, Lingga Jaya, Bandung. Hal. Google Scholar

First publication right:

Jurnal Syntax Fusion: Jurnal Nasional Indonesia

This article is licensed under:

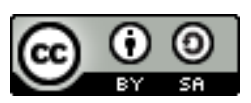

